\title{
Garcinia kola Attenuates MDMA-Induced Neuroinflammation in the CAI Region of the Hippocampus in the Rat Model
}

\author{
Sunday Yinka Olatunji', Iheanyichukwu Okoro', Joshua Oladele Owolabi', John Afees \\ Olanrewaju' (D), Stephen Taiye Adelodun', and Sunday Oluseyi Fabiyi'
}

\begin{abstract}
Background: Garcinia kola (GK) has been experimentally tested for its potential usefulness against oxidative stress-related disorders in a number of body tissues, as well as a number of pathogenic and parasitic diseases. Studies investigating GK extracts' usefulness in combating nervous tissue toxicity, neuroinflammatory disorders, and neuronal degeneration are still inadequate and not yet conclusive.

Purpose: To evaluate the effects of 3,4-methylenedioxymethamphetamine (MDMA)-induced neuroinflammation on the pyramidal neurons and astrocytes of the cornu ammonis I (CAI) region of the hippocampus and the role of GK extract (GKE) in attenuating the effects in the rat model.

Methods: The study was carried out by using 60 healthy adult male Wistar rats, which were randomly assigned into six groups, A, B, C, D, E, and F ( $n=10)$-A (control), B ( $100 \mathrm{mg} / \mathrm{kg}$ body weight of GKE only), C ( $200 \mathrm{mg} / \mathrm{kg}$ body weight of GKE only), D (20 mg/kg body weight of MDMA only), E (100 mg/kg body weight of GKE and $20 \mathrm{mg} / \mathrm{kg}$ body weight of MDMA), and $\mathrm{F}(200 \mathrm{mg} / \mathrm{kg}$ body weight of GKE and $20 \mathrm{mg} / \mathrm{kg}$ body weight of MDMA). Treatment was given for 21 days. Following 24 hours after the last administration, five rats in each group were anesthetized with diether and perfused intracardially, and the brains were excised and fixed in 10 percent neutral buffered formalin for the histological hematoxylin and eosin (H\&E) and immunohistochemical glial fibrillary acidic proteins (GFAP).A thin-slice coronal section of the brain was obtained at the level of the optic chiasma and processed via the paraffin-embedding method. Also, the remaining five brains were used to assess neurotransmitter levels (serotonin and dopamine) and cytochrome c-oxidase. The statistical analysis was done using a oneway analysis of variance (ANOVA).

Results: A significant reduction $(P<.05)$ in body weight was observed in the group that was administered with MDMA when compared with the control and the rest of the treated groups. Dopamine and serotonin levels were significantly decreased $(P<.05)$ in the MDMA-only group when compared with the control and the rest of the treated groups. The control group and groups $B, C$, and $F$ showed intact pyramidal neurons, unlike group $D$, which showed vacuolated and degenerating neurons. The expressions of vacuolation and degeneration in group $D$ were less than those in group $E$, which received a low dose of GKE and MDMA.

Hippocampal astrocytic expressions were significantly higher $(P>.05)$ in the MDMA-only group when compared with the control and other groups.

Conclusion: GKE has significant neuroprotective potential against MDMA-induced toxicity in brain tissue. This is evident in its prevention of MDMA-induced oxidative stress, pyramidal neuronal vacuolation, dispersion, and reactive astrogliosis in
\end{abstract}

the CAI region of the hippocampus. Our findings are dosedependent, with $200 \mathrm{mg} / \mathrm{kg}$ of the extract being novel. We, however, recommend further study into the mechanism of action of GKE, on how it attenuates the astrocytic reaction caused by MDMA exposure.

\footnotetext{
Department of Anatomy, Ben Carson School of Medicine, Babcock University, llisan-Remo, Ogun State, Nigeria Corresponding author:

Olatunji Sunday Yinka, Department of Anatomy, Ben Carson School of Medicine, Babcock University, llisan-Remo, Ogun State, Nigeria.

E-mail: olatunjis@babcock.edu.ng
}

\footnotetext{
cc) (i) (8) Creative Commons Non Commercial CC BY-NC: This article is distributed under the terms of the Creative Commons AttributionNonCommercial 4.0 License (http://www.creativecommons.org/licenses/by-nc/4.0/) which permits non-Commercial use, reproduction and distribution of the work without further permission provided the original work is attributed as specified on the SAGE and Open Access pages (https://us.sagepub.com/en-us/nam/open-access-at-sage).
} 


\section{Keywords}

Garcinia kola, astrocytes, neuroinflammation, hippocampus, MDMA

\section{Introduction}

Garcinia kola (GK) is a dicotyledonous plant found in the tropical regions of Africa, particularly in Nigeria, Ghana, Benin, Ivory Coast, Cameroon, Sierra Leone, Togo, the Congo Democratic Republic, Angola, Liberia, and Gambia. It is traditionally used in these countries for medicinal purposes, and users believe it has potent purgative, antiparasitic, and antimicrobial properties, and that it can be used to treat several infections and liver disorders. ${ }^{1}$ GK has been reported to have antioxidant properties. ${ }^{2,3}$ It has also been suggested to be a useful source of anti-inflammatory agents. ${ }^{4}$ The ethanolic extract, however, has been reported to have significantly higher antioxidant indices than the aqueous extract. ${ }^{2}$ Generally, several studies contain evidence of its nutritional and medicinal benefits..$^{5-9}$ It also has several tested biological activities that could be useful against a number of pathogenic and parasitic diseases. ${ }^{10,11}$

MDMA (3,4-methylenedioxymethamphetamine [ecstasy]) is a psychoactive drug, and it is considered as a suitable experimental alternative to methamphetamine (MAM). The reason is that MAM might not be readily available due to its illegal and highly prohibited status. MDMA has the potential to alter neurotransmitters' re-uptake, especially serotonin, and consequently damage neurons, within a few days of use. ${ }^{12,13}$ While GK has been experimentally tested for its potential usefulness against oxidative stress-related disorders in a number of body tissues, as well as a number of pathogenic and parasitic diseases, its usefulness in combating nervous tissue toxicity, neuroinflammatory disorders, and neuronal degeneration and associated complications has not been extensively explored. In addition to such potential investigations, it is also very important to ascertain the levels of safety of its use relative to the brain, considering its sensitivity to biochemical assaults. This investigation, thus, is crucial towards contributing to knowledge on the potential use of GK extract (GKE) against chemical-induced nervous tissue assaults. The neurotoxic damage caused by MDMA is characterized by nerve terminal destruction and/or degeneration of the dopaminergic and serotonergic systems in the striatum and hippocampus. ${ }^{14,15}$ It also has potent addictive and neurotoxic properties. ${ }^{16}$ More specifically, it causes neuronal degeneration. ${ }^{17}$ The mechanism involved in MDMA neurotoxicity includes reactive oxygen species (ROS), dopamine quinones, glutamatergic activity and apoptosis, inflammatory response of microglia, and glutamatergic toxicity in astrocytes; other associated factors include glial cell line-derived neurotrophic factor (GDNF), tumor necrosis factor alpha, and alpha-synuclein contained in striatal interneural inclusions. ${ }^{18}$ Some of these investigations have considered GK against toxicity on other tissues or structures or its use against the neurotoxicity of substances other than MDMA. For instance, GK was reported to have protective effects on monosodium glutamate-induced cerebellar damage in adult Wistar rats by relatively preserving the cortical tissue when the animals were pretreated with it. ${ }^{19}$ Also, its effects in ameliorating metabolic-related disorders or imbalances were demonstrated in studies on its protective effects on the neurons of the hippocampus and cerebellum of malnourished mice. ${ }^{20}$ This also aligned with and affirmed similar previous investigations..$^{21,22}$ The objective of this study is to evaluate the effects of MDMA-induced neuroinflammation on the pyramidal neurons and astrocytes of the cornu ammonis 1 (CA1) region of the hippocampus and the role of GKE in attenuating the effects in the rat model.

\section{Materials and Methods (See Figure I)}

\section{Care and Management of the Animals}

Sixty healthy adult male Wistar rats (Rattus norvegicus) weighing 100-150 g (5 months old) were used. They were bred in the Animal Holdings of Babcock University IlisanRemo, Ogun State, Nigeria. Proper care of the animals was taken in accordance with the National Institute of Health (US Public Health Service [PHS] policy) on humane care of laboratory animals. The rats were fed a standard pellet diet, and water ad libitum.

\section{Chemicals and Plant Materials}

MDMA was obtained from Sigma-Aldrich, USA, and GK was purchased from Oja Tuntun market in Ile-Ife Osun State, Nigeria. All the reagents and chemicals used in this study were of analytical grade. The kits used for the biochemical tests were enzyme-linked immunosorbent assay (ELISA)

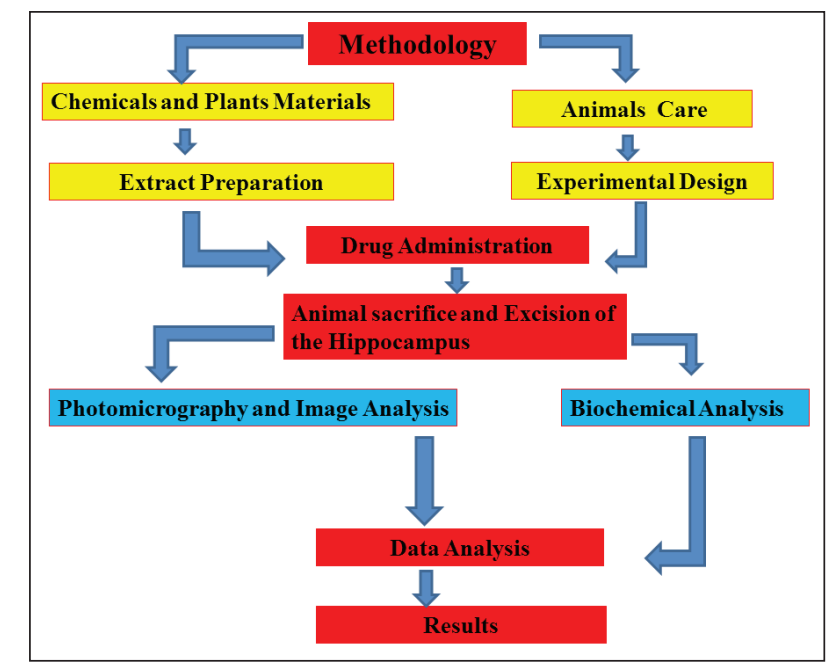

Figure I. A Diagrammatic Illustration of the Research Process with Emphasis on Methodology

Source: Authors own. 
kits, and the antibody for glial fibrillary acidic proteins (GFAP) immunohistochemistry was obtained from Santa Cruz, Vector ${ }^{\circledR}$ Labs, and Fisher Scientific, USA.

\section{Extract Preparation}

GK seeds were peeled and air-dried in the laboratory $\left(25-28{ }^{\circ} \mathrm{C}\right)$ and ground into powdered form. The powdered seeds were extracted with ethanol in a Soxhlet extractor, and $10 \mathrm{~g}$ of the extract was weighed out and dissolved in $100 \mathrm{~mL}$ of normal saline, thus forming $100 \mathrm{mg} / \mathrm{mL}$ of GKE.

\section{Drug Administration}

The rats in the treatment groups received intermittent doses of $20 \mathrm{mg} / \mathrm{kg}$ body weight of MDMA orally. The control group received an equivalent volume of normal saline orally (see Table 1).

\section{Experimental Design}

The study was carried out using 60 healthy adult male Wistar rats, which were randomly assigned into six groups $(n=10)$ : A, B, C, D, E, and F.

Table I. Table Showing the Grouping and Treatment of Experimental Animals

\begin{tabular}{|c|c|}
\hline Groups & Treatment \\
\hline Group A: Control & $\begin{array}{l}\text { This group serves as the control and } \\
\text { was administered normal saline }\end{array}$ \\
\hline $\begin{array}{l}\text { Group B: GKE Low } \\
\text { Dose Treated Rats }\end{array}$ & $\begin{array}{l}100 \mathrm{mg} / \mathrm{kg} \text { body weight daily lower dose } \\
\text { of GKE for } 21 \text { days was administered } \\
\text { to rats to observe the effects of GKE } \\
\text { on the hippocampus. }\end{array}$ \\
\hline $\begin{array}{l}\text { Group C: GKE High } \\
\text { Dose Treated Rats }\end{array}$ & $\begin{array}{l}200 \mathrm{mg} / \mathrm{kg} \text { body weight daily higher } \\
\text { dose of GKE for } 21 \text { days was adminis- } \\
\text { tered to rats to observe its effects on } \\
\text { the Hippocampus. }\end{array}$ \\
\hline $\begin{array}{l}\text { Group D: MD- } \\
\text { MA-Treated Rats }\end{array}$ & $\begin{array}{l}20 \mathrm{mg} / \mathrm{kg} \text { body weight intermittent } \\
\text { dose of MDMA were administered to } \\
\text { rats to observe the neurotoxic effects } \\
\text { of MDMA on rat's hippocampus. Rats in } \\
\text { this group were left untreated. }\end{array}$ \\
\hline $\begin{array}{l}\text { Group E: Low Dose } \\
\text { GKE treated group } \\
\text { and MDMA }\end{array}$ & $\begin{array}{l}\text { Rats were treated pre-treated with } 100 \\
\mathrm{mg} / \mathrm{kg} \text { body weight of GKE throughout } \\
\text { the duration of experiment plus inter- } \\
\text { mittent administration of } 20 \mathrm{mg} / \mathrm{kg} \text { body } \\
\text { weight of MDMA. }\end{array}$ \\
\hline $\begin{array}{l}\text { Group F: High Dose } \\
\text { GKE Treated group } \\
\text { and MDMA }\end{array}$ & $\begin{array}{l}\text { Rats were pre-treated with } 200 \mathrm{mg} / \mathrm{kg} \\
\text { body weight GKE throughout the du- } \\
\text { ration of experiment plus intermittent } \\
\text { administration of } 20 \mathrm{mg} / \mathrm{kg} \text { body weight } \\
\text { of MDMA. }\end{array}$ \\
\hline
\end{tabular}

Source: Authors own.

\section{Excision of the Hippocampus}

Following 24 hours after the last administration, five rats in each group for histology and immunohistochemistry were anesthetized with diether and perfused intracardially with $100 \mathrm{~mL}$ phosphate buffered saline (PBS; 0.1 M, pH 7.4), followed by $250 \mathrm{~mL}$ of neutral buffered formalin. The brains were excised and fixed in 10 percent neutral buffered formalin. A thin-slice coronal section of the brain was obtained at the level of the optic chiasma and processed via the paraffinembedding method. Also, the remaining five brains for neurotransmitters were sacrificed by cervical dislocation; the brains were excised and brain weight was determined.

\section{Hippocampal Biochemical Analysis}

The hippocampus was dissected and homogenized. It was then centrifuged (4,000 rpm for $10 \mathrm{~min}$ ), and its supernatant preserved at $-20^{\circ} \mathrm{C}$ for further biochemical analysis. The neurotransmitters (serotonin, dopamine, glutamate) and enzymes (cytochrome c-oxidase, glucose 6-phosphate dehydrogenase) were analyzed via ENZYME -LINK IMMUNOSORBENT ASSAY (ELISA) at $450 \mathrm{~nm}$ using microplate reader. The analysis was done according to the manufacturer's instructions in the ELISA kits.

\section{Histological and Immunohistochemical Analysis}

Following four days of fixation, tissues were processed for rapid routine tissue processing and were stained for hematoxylin and eosin $(\mathrm{H} \& \mathrm{E})^{23}$ for general histological appearance. The hippocampus was immunohistochemically stained for GFAP for the demonstrations of astrocytic reactions. Paraffin-embedded sections were deparaffinized with xylene and rehydrated through descending grades of ethanol $(100 \%$, $95 \%$, and $70 \%$ ) and taken to water. Heat-mediated antigen retrieval was performed using a citrate-based antigen unmasking solution, pH 6.0 (Vector ${ }^{\circledR}$ Labs, Burlingame, CA; $\#$ H3300) in a steamer for $30 \mathrm{~min}$. Sections were washed in PBS for $2 \mathrm{~min}$. Endogenous peroxidase blocking was done in 0.3 percent hydrogen peroxide solution in PBS for $10 \mathrm{~min}$ and the sections washed in PBS for $2 \mathrm{~min}$. The sections were incubated in 2.5 percent normal horse serum for $20 \mathrm{~min}$ for protein blocking. They were then incubated at room temperature for $2 \mathrm{~h}$ in a primary antibody: mouse monoclonal GFAP-HRP (horseradish peroxidase) conjugated (Santa Cruz, CA) at 1:150. The sections were washed in PBS for $5 \mathrm{~min}$. They were incubated in ImmPRESSTM HRP Anti-Rabbit IgG (Peroxidase) Polymer Reagent, made in horse (Vector ${ }^{\circledR}$ Labs), for $30 \mathrm{~min}$. Sections were washed in PBS for $5 \mathrm{~min} \times$ 2. Colour was developed with DAB (3,3-diaminobenzidine) Peroxidase (HRP) Substrate Kit (Vector ${ }^{\circledR}$ Labs). The sections were rinsed well in tap water. They were counterstained in hematoxylin, dehydrated through ascending grades of ethanol $(70 \%, 95 \%$, and $100 \%)$, cleared in xylene and mounted with 


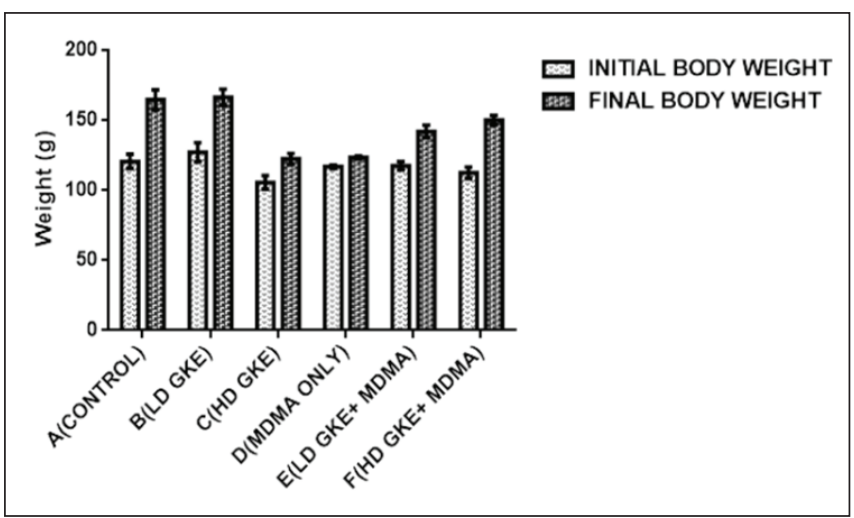

Figure 2: Bar Chart Showing Initial and Final Body Weight Across the Groups.

Source: Authors own.

Notes: $\mathrm{A}=$ Control, $\mathrm{B}$ (LD GKE) = Low dose of Garcinia kola extract, $\mathrm{C}(\mathrm{HD}$ GKE $)=$ High dose of Garcinia kola extract, D(MDMA ONLY) $=$ 3,4-methylenediaxymeth-amphetamine only, $\mathrm{E}(\mathrm{LD}$ GKE+MDMA) = Low dose of Garcinia kola extract and 3,4-methylenediaxymethamphetamine, $F(H D$ GKE+MDMA) High dose of Garcinia kola extract and 3,4-methylenediaxymeth-amphetamine.

Permount (Fisher Scientific, Pittsburgh, PA). Sections without primary antibodies were similarly processed to control for immunohistochemical procedures.

\section{Photomicrography and Image Analysis}

Stained sections were viewed with a Leica DM750 Digital Light microscope, and digital photomicrographs were taken by an attached Leica ICC50 camera. Image Analysis and Processing for Java (ImageJ), a public domain software sponsored by the National Institute of Health (USA), was used to analyze and quantify the photomicrographs. The immunohistochemical stained sections were analyzed for GFAP reactivity using the ImmunoRatio plugin.

\section{Statistical Analysis}

A one-way analysis of variance (ANOVA) was done using GraphPad Prism 5 (GraphPad Inc., San Diego, CA, USA). This was followed by a Student-Newman-Keuls (SNK) test for multiple comparisons. A value of $P<.05$ was considered to indicate significant difference between groups.

\section{Results}

\section{Initial and Final Body Weight and Physical Observation}

Figure 2 shows the initial and final body weights of the animals across the groups. An observable increase in the final body weight was noticed across the groups except in group D (MDMA only). During the second and third week of the experiment, the feeding pattern reduced in group D (MDMA only).

\section{Percentage Weight Gain}

Figure 3 shows the percentage weight gain across the groups. A significant reduction in body weight was observed in the group that was administered only MDMA, compared with the control and the rest of the treated groups. The percentage weight gain in groups C (high-dose [HD] GKE) and D (MDMA only) were significantly lower when compared with that in the control group. The percentage weight gain in group B (low-dose [LD] GKE) was significantly higher than that in group C (HD GKE) and D (MDMA only). The rats administered with MDMA showed no appreciable weight gain (Figures 2 and 3). The percentage weight gain in group C (HD GKE) was significantly higher than that in group D (MDMA only) but significantly lower than that in group F (HD GKE + MDMA). However, the percentage weight gain in group D (MDMA only) was significantly lower than that in groups E (LD GKE + MDMA) and F (HD GKE + MDMA).

\section{Brain Weight}

Figure 4 shows the results of the brain weight across the groups. There was no significant difference in the weight of the brain of the control group when compared with the brain weight of the rest of the treated groups.

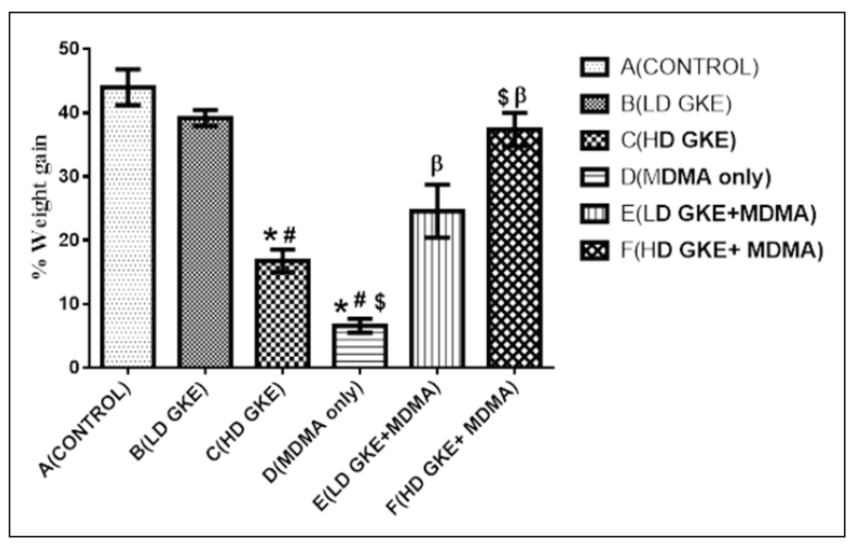

Figure 3: Bar Chart Showing \% Weight Gain Across the Groups.

Source: Authors own.

Notes: Values are expressed as Mean \pm SEM. $A($ Control $)=$ Control, $B(L D$ GKE) = Low dose of Garcinia kola extract, $C(H D$ GKE $)=$ High dose of Garcinia kola extract, D(MDMA ONLY) = 3,4-methylenedioxymethamphetamine only, E(LD GKE+MDMA) = Low dose of Garcinia kola extract and 3,4-methylenedioxymeth-amphetamine, F(HD GKE+MDMA) High dose of Garcinia kola extract and 3,4-methylenedioxymeth-amphetamine. * = significantly different from $A$ (control), \# = significantly different from $B$ (LD GKE), $\$=$ significantly different from C (HD GKE), $\beta=$ significantly different from D (MOMA ONLY) 


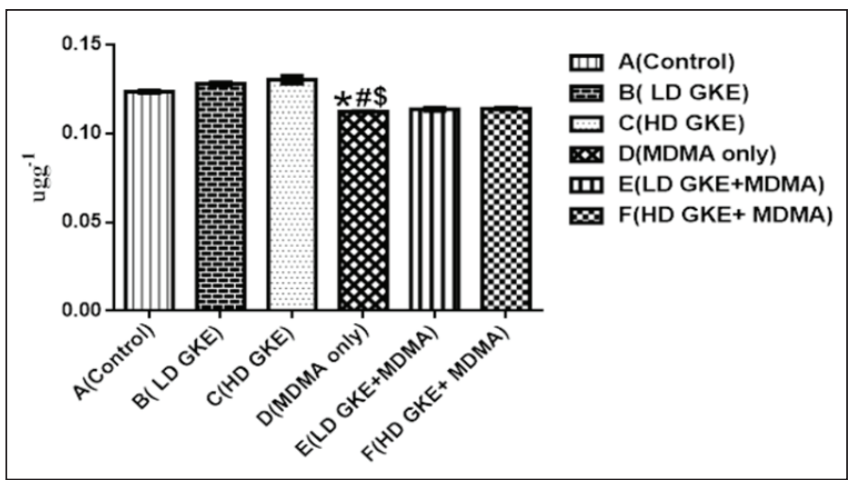

Figure 5: Graph Showing Levels of the Activities of Dopamine Across the Groups.

Source: Authors own.

Notes: $\mathrm{A}($ Control $)=$ Control, $\mathrm{B}(\mathrm{LD}$ GKE $)=$ Low dose of Garcinia kola extract, $\mathrm{C}(\mathrm{HD}$ GKE) = High dose of Garcinia kola extract, D(MDMA $\mathrm{ONLY}$ ) = 3,4-methylenedioxymeth-amphetamine only, E( LD GKE+MDMA) = Low dose of Garcinia kola extract and 3,4-methylenedioxymethamphetamine, F(HD GKE+MDMA) High dose of Garcinia kola extract and 3,4-methylenedioxymeth-amphetamine. $*=$ significantly different from A (control), \# = significantly different from B (LD GK.E) $\$=$ significantly different from $\mathrm{C}(\mathrm{HD}$ GKE), Values are expressed as Mean \pm SEM.

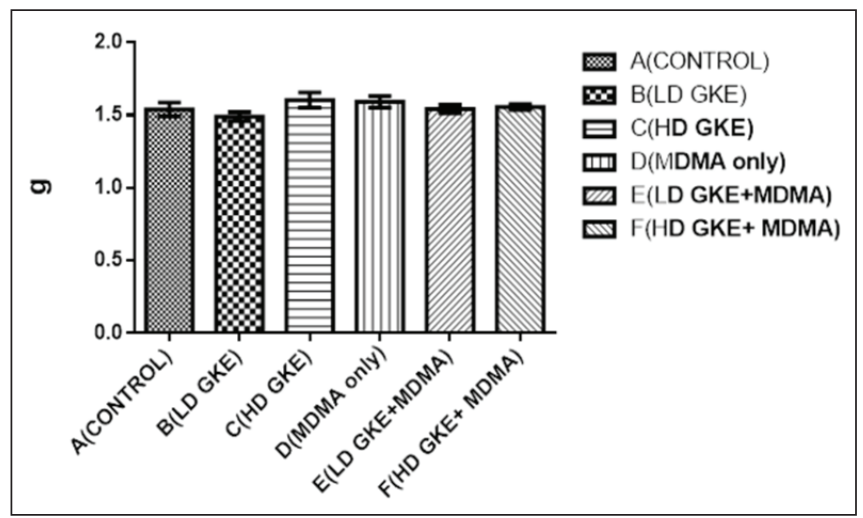

Figure 4: Bar Chart Showing Brain Weight in all the Groups.

Source: Authors own.

Notes: Values are expressed as Mean \pm SEM. A(Control) $=$ Control, $\mathrm{B}(\mathrm{LD}$ GKE $)=$ Low dose of Garcinia kola extract, $\mathrm{C}(\mathrm{HD}$ GKE $)=$ High dose of Garcinia kola extract, D(MDMA only) = 3,4-methylenedioxymethamphetamine only, E( LD GKE+MDMA) =Low dose of Garcinia kola extract and 3,4-methylenedioxymeth-amphetamine, F(HD GKE+MDMA) High dose of Garcinia kola extract and 3,4-methylenedioxymeth-amphetamine.

\section{Dopamine Level}

Figure 5 shows the results of the levels of the neurotransmitter dopamine across the groups. The dopamine level in group D (MDMA only) was significantly lower when compared with that in the control group and groups B (LD GKE) and C (HD GKE). However, no significant difference was observed when the level of dopamine in group D (MDMA only) was compared with that in groups $\mathrm{E}$ (LD GKE + MDMA) and F (HD GKE + MDMA).

\section{Serotonin Level}

Figure 6 shows the results of the level of the neurotransmitter serotonin across the groups. The level of serotonin was significantly higher in the control group when compared with that in groups D (MDMA only), E (LD GKE + MDMA), and F (HD GKE + MDMA). The serotonin level in group D was significantly lower when compared to that in groups B (LD $\mathrm{GKE}$ ) and $\mathrm{C}$ (HD GKE). Also, the serotonin levels in groups $\mathrm{B}$ (LD GKE) and C (HD GKE) were significantly higher than that in the rest of the treated groups, D (MDMA only), E (LD GKE + MDMA), and F (HD GKE + MDMA).

\section{Cytochrome c-Oxidase}

Figure 7 shows the results of the cytochrome c-oxidase level across the groups. Group D showed a significantly higher cytochrome c-oxidase level when compared with that in the control group. However, there was no significant difference when the cytochrome c-oxidase level in the control group was compared with that in groups B, C, E, and F.

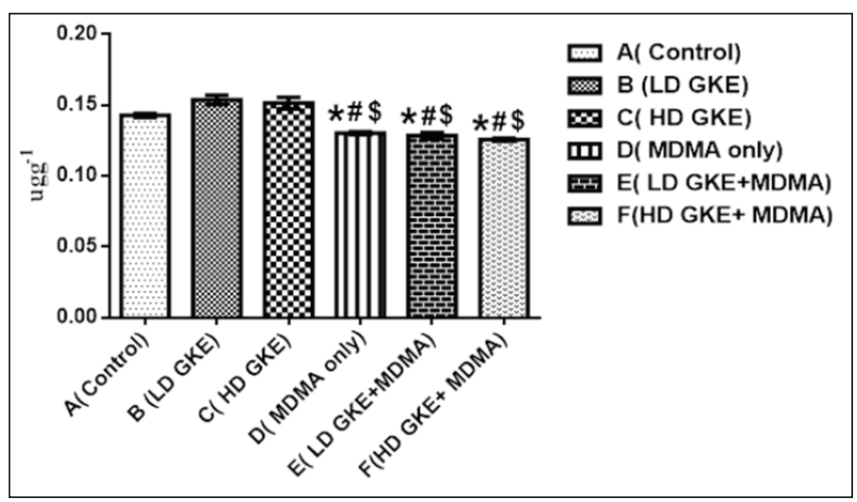

Figure 6: Bar Chart Showing Levels of Serotonin Across the Groups.

Source: Authors own.

Notes: Values are expressed as Mean \pm SEM. $\mathrm{A}($ Control $)=$ Control, $\mathrm{B}(\mathrm{LD}$ GKE $)=$ Low dose of Garcinia kola extract, $\mathrm{C}(\mathrm{HD}$ GKE) $=$ High dose of Garcinia kola extract, D(MDMA only) = 3,4-methylenedioxymethamphetamine only, E( LD GKE+MDMA) = Low dose of Garcinia kola extract and 3,4-methylenedioxymeth-amphetamine, F(HD GKE+MDMA) High dose of Garcinia kola extract and 3,4-methylenedioxymeth-amphetamine. * = significantly different from $A$ (control), \# = significantly different from B (LD GKE), \$ = significantly different from C (HD GKE). 


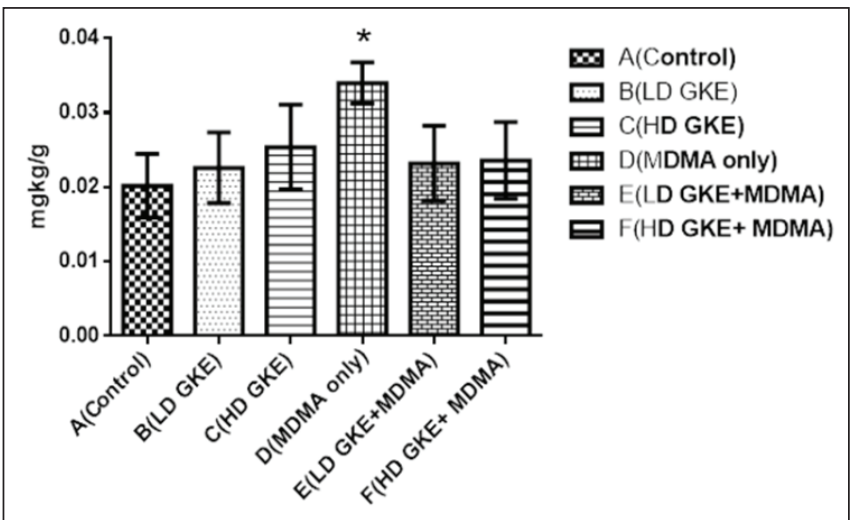

Figure 7: Bar Chart Showing Levels of the Activities of Cytochrome-C-oxidase Across the Groups.

Source: Authors own.

Notes: * =significantly different from $A$ (control), Values are expressed as Mean \pm SEM. A(Control) = Control Group, $B$ (LD GKE ) = Low dose of Garcinia kola extract, C(HD GKE) = High dose of Garcinia kola extract, $D$ (MDMA only) = 3 , 4-methylenedioxymeth-amphetamine only, E ( LD GKE+MDMA) = Low dose of Garcinia kola extract and 3 , 4 -methylenedioxymeth-amphetamine, F (HD GKE+MDMA) High dose of Garcinia kola extract and 3,4-methylenedioxymeth-amphetamine.

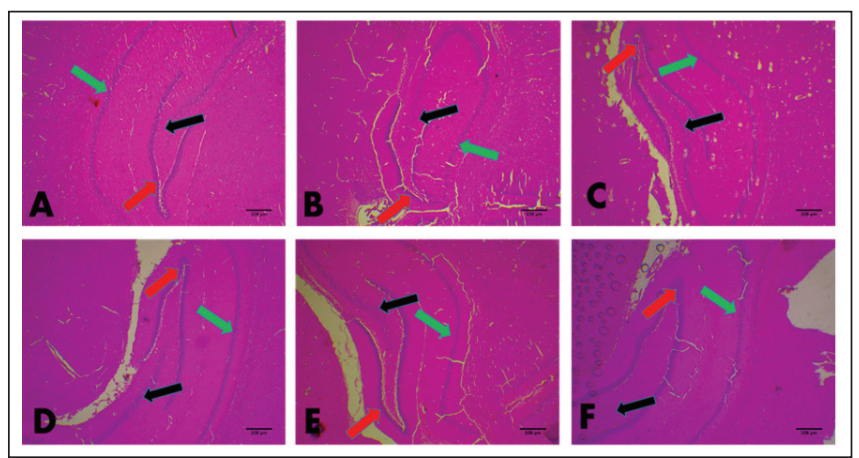

Figure 8: Photomicrograph Showing the General Histoarchitecture of the Hippocampus.

Source: Authors own.

Notes: $A=$ Control, $B=L D$ GKE, $C=$ HD GKE, $D=$ MOMA Only, E = LD GKE + MDMA, F = HD GKE + MDMA, Red arrow = dentate gyrus, green arrow $=\mathrm{CAl}$ and the black arrow $=\mathrm{CA} 4(\mathrm{H \& E}) ;$ Scale bar $=328 \mu \mathrm{m}$

\section{Histological and Immunohistochemical Results}

Figure 8 shows the general histoarchitecture in CA1, CA2, $\mathrm{CA} 3$, and CA4 of the hippocampus and the dentate gyrus at the $328 \mu \mathrm{m}$ scale bar.

Figure 9 shows the CA1 of the hippocampus at the $328 \mu \mathrm{m}$ scale bar. In Figure 9, the control group and groups $\mathrm{B}, \mathrm{C}$, and $\mathrm{F}$ show distinct neuronal cells and a well-arranged pattern of the pyramidal cell in the CA1 region, while groups $\mathrm{D}$ and $\mathrm{E}$ show a more dispersed pattern of arrangement, and this is more prominent in group $\mathrm{D}$, which received MDMA only. Also, in Figure 9, the control group and groups B, $\mathrm{C}$, and $\mathrm{F}$ show intact pyramidal neurons, unlike group $\mathrm{D}$, which shows vacuolated and degenerating neurons. The expressions of vacuolation and degeneration in $\mathrm{D}$ were less than those in group E, which received a low dose of GKE and MDMA. Pyramidal neuron dispersion was noticed in groups $\mathrm{D}$ and $\mathrm{E}$ but was absent in the control group and groups $\mathrm{B}, \mathrm{C}$, and $\mathrm{F}$.

Figure 10 shows the photomicrographs of the GFAP immunohistochemically stained slide that demonstrates astrocytes at the $32 \mu \mathrm{m}$ scale bar. The positive expressions of GFAP were prominent in group D, the group treated with MDMA only. Evidence of reactive astrogliosis was noticed in group D, which was not present in the other groups. GFAP was more expressed in group D (MDMA only), with an increase in the size of astrocytes, as well as in the astrocytic numbers.

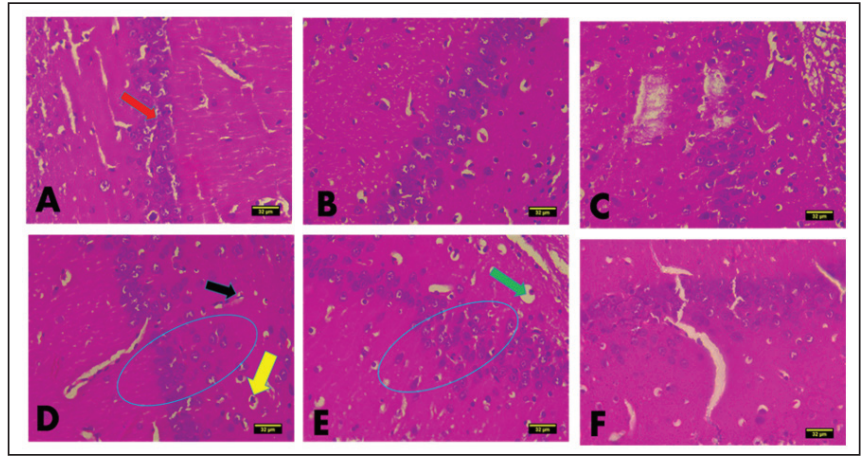

Figure 9: Photomicrographs Showing the General Histoarchitecture of the Cornu Arnmonis I (CAI) Region of the Hippocampus.

Source: Authors own.

Notes: $A=$ Control, $B=$ LD GKE, C $=$ HD GKE, $D=$ MDMA Only, E = LD GKE + MDMA, F = HD GKE + MDMA. Red arrow = Intact neuron (pyramidal neuron), black arrow $=$ pyknotic neuron, Yellow arrow $=$ degenerating neuron, Green Arrow = vacuolated neuron, Blue circle indicates pyramidal cell dispersion in the CAI (H\&E) Scale bar $=32 \mu \mathrm{m}$.

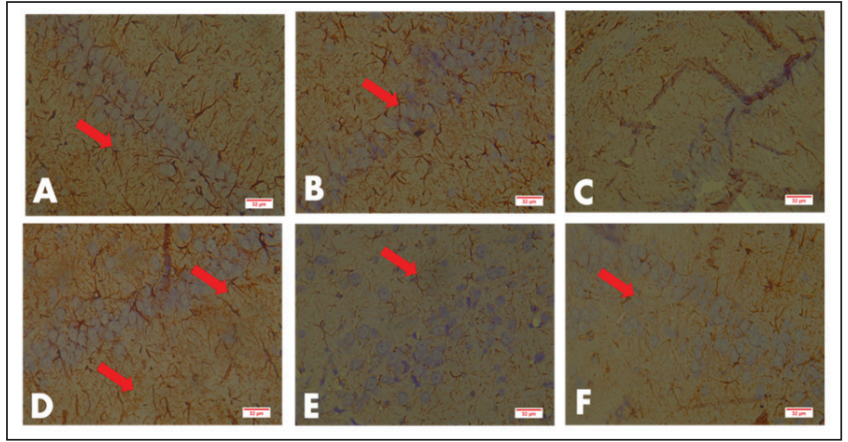

Figure 10: Photomicrographs of the CA I of the Hippocampus Showing the Expression of Astrocytes in the Glial Fibrillary Acidic Protein (GFAP) Immunohistochemically Stained Slides.

Source: Authors own.

Notes: $A=$ Control, $B=$ LD GKE, $C=$ HD GKE, D.= MDMA Only, E = LD GKE + MDMA, F = HD GKE + MDMA. Green arrow shows astrocytic cells (GFAP) Scale bar $=32 \mu \mathrm{m}$. There is enhanced GFAP expression in Group D which is an indication of astrocyte reactivity and neuroinflammation 


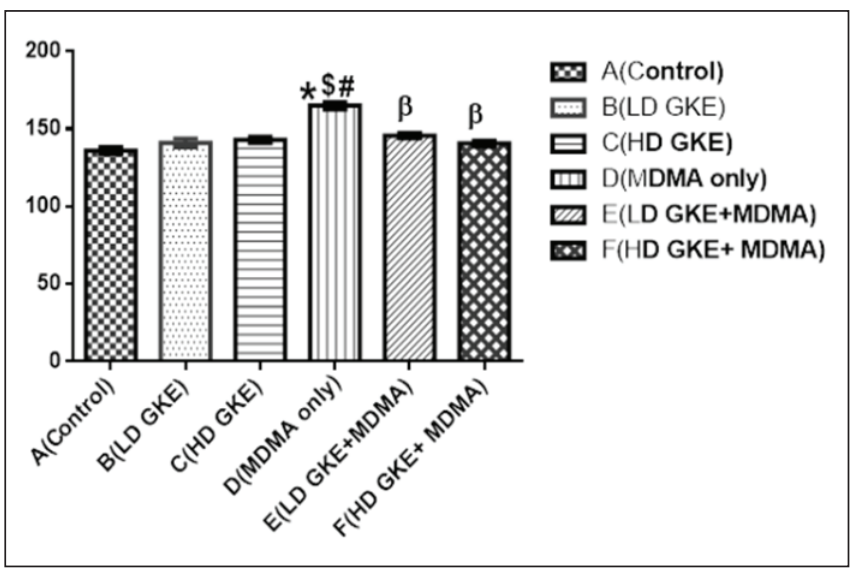

Figure I I: Bar Chart Showing Glia Fibrillary Acidic Protein (GFAP) Immunoreactivity (immunoratio plugin) Across the Groups.

Source: Authors own.

Notes: $*=$ significantly different from A (control), \# = significantly different from $B$ (LD GKE) $\$=$ significantly different from $C$ (HD GKE), $\beta=$ significantly different from $D$. Values are expressed as Mean \pm SEM. $\mathrm{A}($ Control $)=$ Control, $\mathrm{B}(\mathrm{LD}$ GKE $)=$ Low dose of Garcinia kola extract, $\mathrm{C}(\mathrm{HD}$ GKE $)=$ High dose of Garcinia kola extract, $\mathrm{D}($ MDMA ONLY $)=$ 3,4-methylenedioxymethamphetamine only, E( LD GKE+MDMA) = Low dose of Garcinia kola extract and 3,4-methylenedioxymeth-amphetamine, F(HD GKE+MDMA) High dose of Garcinia kola extract and 3,4-methylenedioxymet h-am ph eta mine.

\section{Astrocytes' Reactivity in CAI of the Hippocampus with the ImmunoRatio Plugin}

Figure 11 shows the GFAP immunoreactivity across the groups, which was significantly lower in the control group than in the group treated with MDMA only. Hippocampal astrocytes were significantly higher in the MDMA-only group when compared with those in groups B and C. However, the number of astrocytes, or astrocytic reactivity, was higher in the MDMA-only group when compared with that in the groups that were pretreated with GKE before the administration of MDMA.

\section{Discussion}

This study investigated the protective role of GKE in MDMA-induced hippocampal damage, especially on the major glial cells of the hippocampus, which are astrocytes. Ecstasy is a commonly used psychoactive drug with 3,4-methylenedioxymethamphetamine as the main content. ${ }^{24}$ Euphoric feelings and the ability to socialize can increase after the use of MDMA. ${ }^{24}$ It has been reported that MDMA suppresses the sense of appetite. ${ }^{25-27}$ Loss of appetite can bring about a reduction in food intake, which may eventually result in reduced body weight. In this study, there was no appreciable increase in the final body weight of the MDMAonly group compared with that in the rest of the treated groups. This may be due to the fact that MDMA suppresses appetite by acting on the feeding center in the ventromedial nucleus of the hypothalamus. ${ }^{28}$ Also, the significant decrease observed in the weight gain of the rats treated with MDMA only compared with those in the control and the rest of the treated groups may be due to euphoria, which may be linked to MDMA's effects on the limbic system, of which the hippocampus is a key component, of increased energy, increased metabolic activities ${ }^{27}$ and decreased food intake, which lead to a significant reduction in body weight. The significantly higher weight gain observed in the rats in groups $\mathrm{E}(\mathrm{LD}$ GKE + MDMA) and F (HD GKE + MDMA) pretreated with GKE before the administration of MDMA, compared with that in the rats treated with MDMA only, could probably be due to the antioxidant role of GKE, ${ }^{29}$ which has the ability to protect neurons of the brain from toxic damage that could arise from MDMA administration.

Serotonin (5-HT), a monoamine neurotransmitter, has been reported to contribute to feelings of well-being and happiness and modulate cognition, rewards, learning, and memory. ${ }^{30}$ Also, MDMA has been associated with both desirable effects (euphoria, increased energy, and sexual arousal) and undesirable psychological effects such as confusion, mental fatigue, anxiety, and depression. ${ }^{31}$ Serotonin is not only known to autoregulate the outgrowth of serotonergic neurons but has also been implicated in the control of cell proliferation, differentiation, migration, cell death, synaptogenesis, and dendritic pruning. ${ }^{32,33}$ Findings from the literature support the fact that MDMA administration results in the degeneration of serotonin neurons in the brains of rodents and primates. ${ }^{34,35} \mathrm{In}$ this study, the significant decrease in the level of serotonin in the rats treated with MDMA only, compared with that in the control group rats, supports the proposition that MDMA administration, at both acute and chronic doses, depletes serotonin in the brain ${ }^{34,36}$ by acting on the serotonergic pathway and increasing lipid peroxidation, which reflects increased free radicals. ${ }^{37}$ This study showed no significant difference between serotonin level in the control group and that in the groups that received GKE at high and low doses (see Figure 6). This is an indication that GKE does not have any negative effects on serotonin. Also, there was no appreciable difference in the level of serotonin in the groups that were treated with GKE before the administration of MDMA and that in the group that received MDMA only; this could be due to the fact that GKE was not able to prevent serotonin depletion in the latter group.

Some studies have reported that the administration of ecstasy affects not only the serotonin system but also the dopamine system. Commins et al. ${ }^{12}$ reported that when MDMA was given to rats at a high dosage, dopamine level was decreased in some brain region. However, other findings have reported that the administration of MDMA has limited effects on dopamine nerve endings in the rat model. ${ }^{38,39}$ In this study, dopamine levels in the MDMA-only group showed a significant decrease when compared with that in the control group and groups B and C that received only GKE. Our finding is in agreement with that of other studies 
that showed depletion in the dopamine level after MDMA administration. ${ }^{12,25,40}$

Pyramidal neurons and granule cells are the main cells of the CA and the dentate gyrus of the hippocampus, respectively. The former, being the main cell of the CA1 region, showed dispersion in arrangement and vacuolation and degeneration features in the group that was treated with MDMA only. These features were absent in the control group and groups $\mathrm{B}, \mathrm{C}$, and F. Also, in Figure 9, the control group and groups B, C, and $\mathrm{F}$ show distinct pyramidal neurons, unlike group $\mathrm{D}$, which shows vacuolated and degenerating neurons. The expressions of vacuolation and degeneration in group $\mathrm{D}$ were less than that in groups $\mathrm{E}$ and $\mathrm{F}$, which received MDMA after receiving a low dose and a high dose, respectively, of GKE. These features appear mild in group $\mathrm{F}$ that was treated with a high dose of GKE before the administration of MDMA. This is suggestive of the attenuating nature of GKE. All these taken together showed that neuronal degeneration caused by MDMA administration was prevented by the administration of GKE. The protective property of GKE is believed to be due to its antioxidant content that probably prevented neuronal degeneration and vacuolation and pyramidal cell dispersion in group $\mathrm{F}$.

Glial cells constitute about 50 percent of the cells in the human brain, with astrocytes occupying the largest glial population. ${ }^{41}$ Astrocytes fill the space between neurons, and they play essential roles in regulating the extracellular space, thereby restricting the spread of neurotransmitter molecules that have been released. ${ }^{42}$ When there is a defect in astrocyte generation, it brings about severe neurological disorders, such as brain tumors..$^{43}$ GFAP is a suitable proof of neuroinflammation, in response to which there is an astrocytic reaction. Although astrocytic reaction is a universal response to many types of brain injury, little has been done to further investigate the response of GKE on glial cells in MDMAinduced brain damage. Reactive astrogliosis manifests as cell swelling, hypertrophy of cellular process and hyperplasia, and changes associated with increased expression of GFAP. ${ }^{44}$ Astrocytic hypertrophy can occur as a result of neuronal injury, leading to increased GFAP expression, and several studies have shown increased GFAP content following MDMA administration in mice and rats ${ }^{45}$ Hypertrophy of the astrocytes and the well-expressed GFAP in the group treated with MDMA only in our study are supported by previous studies that reported that MDMA-induced neurotoxicity is accompanied by astrogliosis. ${ }^{46,47}$ Microglia and astrocytic cells are the two major types of reactive glial cells, while oligodendrocytes do not show reactive changes following an injury to the central nervous system. ${ }^{48}$ In this study, rats that were administered GKE only showed hippocampal morphology that was similar to that in the control group. The findings on astrocytes in our study is in agreement with previous studies that reported highly expressed GFAP, which are characterized by astrocytic swellings, hyperplasia, and astrocytic hypertrophy in MDMA-induced brain damage ${ }^{43,44,47}$ These features were observed in the group that received MDMA only, and the astrocytic reactions (as observed in Figures 10 and 11) were less expressed in groups $\mathrm{E}$ and $\mathrm{F}$ that were pretreated with GKE. This is an indication of the neuroprotective ability of GKE against MDMA-induced hippocampal neurotoxicity. In this study, the changes observed in the hippocampal morphology of the MDMA-only group were characteristic features of reactive astrogliosis, and these were absent in the control group and were mild or attenuated in the CA1 region of the hippocampus of the rats pretreated with a low or high dose of GKE before MDMA administration. This is suggestive of the neuroprotective ability of GKE. The neuroprotective potentials of GKE is postulated to be largely attributable to its antioxidant phytochemical constituents that act by their abilities to mitigate MDMA-induced neurotoxicity by the production of reactive oxygen species that results in oxidative stress. Several studies in humans and animals have shown evidences that consumption of flavonoid from fruits, vegetables, herbs, and plant-derived beverages is important to neuronal health. ${ }^{49-51}$

\section{Conclusion}

In conclusion, this investigation has shown that GKE has significant neuroprotective potential against MDMA-induced toxicity in nervous tissues. This is evident in its prevention of MDMA-induced oxidative stress, pyramidal neuronal vacuolation, dispersion, and reactive astrogliosis in the CA1 region of the hippocampus. Our findings are dose-dependent, with $200 \mathrm{mg} / \mathrm{kg}$ of the extract being novel. We, however, recommend further study into the mechanism of action of GKE, on how it attenuates the astrocytic reaction caused by MDMA exposure.

\section{Author Contributions}

OSY conducted the experiments, performed biochemical investigations, and assisted in the writing of the manuscript. OI designed the study and arranged the funding. He had a lead role in drafting the article and reviewed the final manuscript. OJO played an active role in the arrangement of resources and served as the project's supervisor. OJA performed statistical analysis and contributed to the interpretation of the results. AST performed the immunohistochemical and histological studies, interpreted the immunohistochemical results with the scale bar, and wrote the comments. FSO prepared figures and helped in the writing of the manuscript.

\section{Declaration of Conflicting Interests}

The authors declared no potential conflicts of interest with respect to the research, authorship and/or publication of this article. 


\section{Ethical Statement}

In this study, all animal procedures and experiments were performed by adopting international ethical guidelines of the National Institutes of Health on the care and use of laboratory animals, and the study protocol was approved by the Babcock University Ethical Research Committee (approval number BUHREC 716/19).

\section{Funding}

The authors disclosed receipt of the following financial support for the research, authorship, and/or publication of this article: This project was funded by the Research Innovation and International Cooperation (RIIC) of Babcock University, Nigeria. Grant number: BU/ RIIC/2018/04.

\section{ORCID iD}

Olanrewaju John Afees (iD https://orcid.org/0000-0002-9540-4117

\section{References}

1. Iwu M, Duncan AR, and Okunji CO. New antimicrobials of plant origin. Alexandria, VA: ASHS Press, 1999: 457-462.

2. Ogunmoyole T, Olalekan OO, Fatai O, Makun JO, Kade IJ. Antioxidant and phytochemical profile of aqueous and ethanolic extract of Garcinia kola. J Pharmacognos Phytother 2012; 4(5): 66-74.

3. Okoko T. Chromatographic characterisation, in vitro antioxidant and free radical scavenging activities of Garcinia kola seeds. Afr J Biotechnol 2009; 8: 7133-7137.

4. Adesuyi AO, Elumm IK, Adaramola FB, et al. Nutritional and phytochemical screening of Garcinia kola. Adv J Food Sci Technol 2012; 4(1): 9-14.

5. Mazi EA, Okoronkwo KA, and Ibe UK. Physico-chemical and nutritive properties of bitter kola (Garcinia kola). J Nutr Food Sci 2013; 3: 218.

6. Olatunde FE, Akannni OO, and Emerole GO. Antioxidant and scavenging activities of flavonoid extract (kolaviron) of Garcinia kola seeds. Phamaceut Biol 2002; 40: 107-116.

7. Ogu EO and Agu RC. A composition of some chemical properties of Garcinia kola and Hps for assessment of garcinia brewing value. Biores Technol 1995; 54: 1-4.

8. Braide VB. Anti-inflammatory effect of kolaviron: a bioflavonoid extract of Garcinia kola. Fitoterapia 1993; LXIV: 433-436.

9. Aina JO and Uko EE. Preliminary studies on tropical Hop substitutes. Trop Sci 31991; 1: 379-385.

10. Dah-Nouvlessounon D, Baba-Moussa F, Adjanohoun A, et al. Phytochemical screening and biological activities of Garcinia kola (bark, leaves and seeds) collected in Benin. Afr J Microbiol Res 2015; 9(28): 1716-1727.

11. Adegboye MF, Akinpelu DA, and Okoh AI. The bioactive and phytochemical properties of Garcinia kola (Heckel) seed extract on some pathogens. Afr J Biotechnol 2008; 7(21): 3934-3938.

12. Commins DL, Vosmer G, Virus RM, et al. Biochemical and histological evidence that methylenedioxymethylamphetamine (MDMA) is toxic to neurons in the rat brain. J Pharmacol Exp Ther 1987; 241: 338-345.

13. Hatzidimitriou G, McCann UD, and Ricaurte GA. Altered serotonin innervation patterns in the forebrain of monkeys treated with $(+/-) 3,4-$ methylenedioxymethamphetamine seven years previously: factors influencing abnormal recovery. J Neurosci Off J Soc Neurosci 1999; 19(12): 5096-5107.

14. Kita T and Nakashima T. A recent trend in methamphetamineinduced neurotoxicity [article in Japanese]. Nihon Shinkei Seishin Yakurigaku Zasshi 2002; 22(2): 35-47.

15. Volz TJ, Fleckenstein AE, and Hanson GR. Methamphetamineinduced alterations in monoamine transport: implications for neurotoxicity, neuroprotection and treatment. Addiction 2007; 102(Suppl 1): 44-48.

16. Kitamura O. Detection of methamphetamine neurotoxicity in forensic autopsy cases. Leg Med (Tokyo) 2009; 11(Suppl 1): S63-S65.

17. Larsen KE, Fon EA, Hastings TG, et al. Methamphetamineinduced degeneration of dopaminergic neurons involves autophagy and upregulation of dopamine synthesis. J Neurosci 2002; 22(20): 8951-8960.

18. Kita T, Takeshima M, Wagner GC, et al. New perspectives on the mechanism of methamphetamine-induced neurotoxicity. Nihon Shinkei Seishin Yakurigaku Zasshi 2008; 28(2): 49-61.

19. John AA, Bamidele FP, and Ridwan SO. Neuroprotective effect of aqueous extract of Garcinia kola on monosodium glutamate - induced cerebellar cortical damage in adult Wistar rats. Eur J Med Plants 2015; 5(1): 13-22.

20. Ajayi SA, Ofusori DA, Ojo GB, et al. The microstructural effects of aqueous extract of Garcinia kola (Linn) on the hippocampus and cerebellum of malnourished mice. Asian Pac J Trop Biomed 2011; 1(4): 261-265.

21. Adaramoye OA. Protective effect of kolaviron, a biflavonoid from Garcinia kola seeds, in brain of Wistar albino rats exposed to gamma-radiation. Biol Pharm Bull 2010; 33(2): 260-266.

22. Nwoha PU, Ojo GB, Ajayi SA, et al. Garcinia kola diet provides slight neuroprotection to mice hippocampal neurons against neurotoxin. J Environ Neurosci Biomed 2007; 1(2); 125-136.

23. Bancroft JD and Gamble M. Theory and practice of histological techniques. 6th ed. China: Churchill Livingstone, Elsevier, 2008.

24. Vegting Y, Reneman L, and Booij J. The effects of ecstasy on neurotransmitter systems: a review on the findings of molecular imaging studies. Psychopharmacology 2016; 233: 3473-3501.

25. Favrod-Coune $\mathrm{T}$ and Broers B. The health effect of psychostimulants: A literature review. Pharmaceuticals 2010; 3: 2333-2361. 
26. Harold K. The pharmacology and toxicology of 'ecstasy' (MDMA) and related drugs. Can Med Assoc J 2001; 165(7): 917-928.

27. Baylen CA and Harold R. A review of the acute subjective effects of MDMA/ecstasy. Addiction 2006; 101: 933-947.

28. Guyton AC and Hall JE. Textbook of medical physiology. 11th ed. Philadelphia, PA: WB Saunders Company, 2006.

29. Farombi EO, Shrotriya S, and Surh YJ. Kolaviron inhibits dimethyl nitrosamine induced hepatotoxicity by suppressing COX-2 and iNOS expression: NF-kB and AP-1 as potential molecular targets. Life Sci 2009; 84: 149-155.

30. Young SN. How to increase serotonin in the human brain without drugs? J Psychiatry Neurosci 2007; 32(6): 394-399.

31. Gold MS, Tabrah H, and Frost-Pineda K. Psychopharmacology of MDMA (ecstasy). Psychiatr Ann 2001; 31: 675-681.

32. Homberg JR, Schubert D, and Gaspar P. New perspectives on the neurodevelopmental effects of SSRIs. Trends Pharmacol Sci 2010; 31: 60-65. doi:10.1016/j.tips.2009.11.003

33. Whitaker-Azmitia PM, Druse M, Walker P, et al. Serotonin as a developmental signal. Behav Brain Res 1996; 73: 19-29.

34. Green AR, Cross AJ, and Goodwin GM. Review of the pharmacology and clinical pharmacology of 3,4-methylenedioxymethamphetamine (MDMA or "ecstasy"). Psychopharmacology 1995; 119: 247-260.

35. Green AR and Goodwin GM. Ecstasy and neurodegeneration. Br Med J 1996; 312: 1493-1494.

36. National Institute on Drug Abuse (NIDA). The neurobiology of ecstasy (MDMA), https://www.drugabuse.gov (2007).

37. Colado MI, O'Shea E, Granados R, et al. A study of the neurotoxic effect of MDMA ('ecstasy') on 5-HT neurons in the brains of mothers and neonates following administration of the drug during pregnancy. Br J Pharmacol 1997; 121: 827-833.

38. Battaglia G, Yeh SY, O'Hearn E, et al. 3,4-Methylenedioxymethamphetamine and 3,4-methylenedioxyamphetamine destroy serotonin terminals in rat brain: quantification of neurodegeneration by measurement of $[3 \mathrm{H}]$ paroxetine-labeled serotonin uptake sites. J Pharmacol Exp Ther 1987; 242: 911-916.
39. Stone DM, Stahl DC, Hanson GR, et al. The effects of 3,4-methylenedioxymethamphetamine (MDMA) and 3,4-methylenedioxyamphetamine (MDA) on monoaminergic systems in the rat brain. Eur J Pharmacol 1986; 128: 41-48.

40. Knorr U and Kessing LV. The effect of selective serotonin reuptake inhibitors in healthy subjects. A systematic review. Nord J Psychiatry 2010; 64: 153-163.

41. Azevedo FAC, Carvalho LRB, Grinberg LT, et al. Equal numbers of neuronal and nonneuronal cells make the human brain an isometrically scaled-up primate brain. J Comp Neurol 2009; 513: 532-541.

42. Bear MF, Connors BW, and Paradiso MA. Neuroscience: exploring the brain. 6th ed. Philadelphia, PA: Lippincott Williams \& Wilkins, 2007.

43. Schwartzbaum JA, Fisher JL, Aldape KD, et al. Epidemiology and molecular pathology of glioma. Nat Clin Pract Neurol 2006; 2: 494-503.

44. Norton WT, Aquino DA, Hozumi I, et al. Quantitative aspects of reactive gliosis: a review. Neurochem Res 1992; 17: 877-885.

45. Jahanshahi M, Nikmahzar EG, Babakordi F, et al. Ecstasy, anxiety and rat hippocampal astrocytes European. J Anat 2013; 17(1): 23-28.

46. Norton WT. Cell reactions following acute brain injury: A review. Neurochem Res 1999; 24: 213-218.

47. Ofusori DA, Adelakun AE, Ayoka AO, et al. Waterleaf(Talinum triangulare) enhances cerebral functions in Swiss albino mice. J Neurol Sci Turk 2008; 25(4): 239-246.

48. Ijomone O, Nwoha P, Olaibi O, et al. Neuroprotective effects of kolaviron, a biflavonoid complex of Garcinia kola, on rats hippocampus against methamphetamine-induced neurotoxicity. Maced J Med Sci 2012; 5(1): 10-16.

49. Anand A, Banik A, Thakur K, L Masters C. The animal models of dementia and Alzheimer's disease for pre-clinical testing and clinical translation. Curr Alzheimer Res. 2012 Nov 1; 9(9): 1010-1029.

50. Anand A, Saraf MK, Prabhakar S. Sustained inhibition of brotizolam induced anterograde amnesia by norharmane and retrograde amnesia by 1-glutamic acid in mice. Behav. Brain Res. 2007 Aug 22; 182(1):12-20.

51. Anand A, Saraf MK, Prabhakar S. Antiamnesic effect of B. monniera on L-NNA induced amnesia involves calmodulin. Neurochem Res. 2010 Aug 1; 35(8): 1172-1181. 